\title{
Taiwan Foundry for System-In-Package (SIP)
}

\author{
Albert W. Lin \\ APack Technologies Inc. \\ Hsinchu, Taiwan, ROC \\ Tel: 886-3-578-8766 \\ Fax: 886-3-563-2129 \\ E-mail: Alin@apack.com.tw
}

\begin{abstract}
System-In-Package (SIP) is a cost-effective alternative to System-On-Chip (SOC) and chips with embedded memory. The key elements of SIP technology include I/O redistribution, solder bumping, flip chip assembly, and high density thin film interconnect substrate with/without integrated passives. To meet the need of SIP, as well as other advanced packaging solutions, APack Technologies has been set up to serve worldwide customers. High quality of the APack's service is built upon the SIP technology licensed from Bell Labs of Lucent Technologies, and the experience of cost competitive wafer fabrication of foundries in Taiwan.
\end{abstract}

\section{Introduction}

To achieve System-On-Chip (SOC) performance has been the ultimate goal of IC designers. Recently, personal computers and related components are beginning to be manufactured using SOC. However, it is soon realized that the SOC approach does not provide cost savings as expected, and even may not be "the best solution." For example, graphic processors integrated with DRAM for high performance 3D applications, or other logic chips with embedded memories, demand compromising in terms of chip design, mask level, wafer processing, chip size, yield and testing. This is especially true when the price of DRAM reaches bottom of market. It is not economically wise to integrate different function blocks with large price differential on one piece of silicon real estate.

As more devices are packed in BGA (ball grid array) packages to meet the challenge of high pin count and to improve SMT (surface mount technology) assembly yield at board level, an evolution of micro BGA or Chip Scale Package (CSP) quickly push the microelectronic packaging to higher level of integration. Solder bumping technology is the key driver behind all these advancement of integration. When wafer bumping service becomes available recently, Wafer Level Packaging (WLP) is gaining a lot of attention. This ultimate form of IC device packaging can be realized now. Suddenly packaging becomes an extension of wafer process.

With flip chip assembly, it is very easy to integrate solderbumped chips into a compact size. In fact, the short interconnect distance (about $50 \mu \mathrm{m}$ ) along with low inductance (ca. $0.1 \mathrm{nH}$ ) provided by the solder joints results in better signal propagation than any other means. The flip chip assembly can be carried out on wafer level. A combination of wafer level bumping and assembly is the foundation of SIP technology. This packaging solution offers a very attractive alternative to SOC in terms of cost and performance. In addition, it offers a freedom of integrating very different IC technologies such as, CMOS and Bipolar, or even $\mathrm{Si}$ and $\mathrm{GaAs}$ devices.

In this paper, we will introduce APack Technologies, an advanced packaging foundry that offers a complete manufacturing technology of wafer level packaging and assembly to meet the need of system integration. Its SIP process, design rules and reliability data will be discussed.

\section{Foundry Setup}

Solder bumping technology was first developed and applied onto large computer system in early 70's by IBM. However, its C4 (controlled collapse chip carrier) technology using evaporation to form solder bumps had been captive for internal use until recently. Many other bumping technologies, such as plating, printing, dispensing, ball placement, etc. have been developed.

In view of increasing market demand and unavailability of solder bumping and flip chip assembly, APack Technologies was set up in October 1996 to provide manufacturing service of wafer level packaging. A complete set of technologies, including low cost solder bumping by printing lead-free solder paste, were transferred from Bell Labs of Lucent Technologies.

\section{SIP Process and Design Rules}

The key elements of APack SIP Technology are I/O Redistribution, Solder Bumping, and Flip Chip Assembly. All of the processes are conducted at wafer level. Before the SIP processing is started, all wafers should be functionally tested, and the test results in wafer map format should be received. Bad chips on the wafers can be marked with 
special ink. Preferably, wafers should have a minimum thickness of $508 \mu \mathrm{m}$ (20 mils) with little or no backside thinning.

Wafers of the chips to be mounted on another chip or $\mathrm{Si}$ substrate are processed for redistribution of I/O pads first. If the chips need to be burn-in tested before assembly or tall solder joints are required, the wafers are solder bumped using a printing method, then are diced into individual chips.

Once the wafers are diced, good chips can be picked and then placed on a wafer of another chip or a Si interconnect substrate (called Base Wafer) for flip chip assembly. After assembly, these chips can be tested to confirm their functionality. Once the base wafer is diced, the chip assemblies (called Tiles) can be picked and placed in a conventional package such as a PQFP or a BGA using wire bonding. APack also offers the Tiles in advanced packages such as flip chip BGA and Chip Size Module (CSM) using solder assembly instead of wire bonding.

The SIP process flow is illustrated in Figure.1 and Figure.2.

\section{A. Key Materials}

Polyimide is used as inter-level dielectric material to ensure the electrical performance of the integrated devices in SIP as good as their original ones in individual packages. Polyimide has been widely used as part of the passivation/encapsulation material of $\mathrm{Si}$ devices, and especially on DRAM chips where it also serves as a protection layer to reduce soft errors caused by alpha particles. Photosensitive polyimide is used to reduce processing steps and save cost. The polyimide needs to be processed at $350^{\circ} \mathrm{C} 1$ hour in nitrogen for a final cure. Each of the wafers may be subject to the final cure process no more than two times after receiving by APack. For the wafers with limited thermal budget, this heat treatment should be taken into consideration.

The under bump metallization (UBM) is a multilevel structure of sputtered $\mathrm{Cr}, \mathrm{Cr}-\mathrm{Cu}$, and $\mathrm{Cu}$ thin films. The UBM provides an interface between the solder bump and the aluminum I/O pad. While $\mathrm{Cr}$ provides excellent adhesion to Al pad, $\mathrm{Cu}$ offers a solder wettable surface. This UBM structure ensures a strong solder joint to the chips.

Two types of solder material are available for wafer bumping, i.e. $\mathrm{SnSb}$ and $\mathrm{SnPb}$. Their composition, melting points and reflow temperatures are given in Table.1. The $\mathrm{SnSb}$ solder is specially formulated for applications where a lead-free environment is required or the device performance is sensitive to alpha particle radiation such as DRAM chips.

\section{B. Design Rules}

Most of the APack SIP design rules are dictated by the limitations of manufacturing processes and materials. Table. 2 lists the composition and design values of each mask level.

To enhance process yield and reliability, chip I/O pads are redistributed to form an area array of solder-wettable pads. The I/O rerouting paths normally avoid crossing over performance-sensitive areas in the chip. However, preliminary data indicate that the rerouting paths over laser repair windows and memory cells do not degrade the performance of $100 \mathrm{MHz}$ SDRAM devices. Details of the I/O redistribution design rules are illustrated in Table. 3 and Figure.3.

It is preferred to redistribute chip I/O pads in order to enhance flip chip assembly yield and reliability. However, $\mathrm{I} / \mathrm{O}$ redistribution may be omitted to save two processing steps and cost, when the pitch of original I/O pads is adequate for solder bumping (with a minimum pitch of 150 $\mu \mathrm{m})$. For ultra high-speed devices such as RF chips, extra parasitic from the rerouting path should be minimized. In this case, solder wettable UBM pads and solder are deposited directly on the original $\mathrm{I} / \mathrm{O}$ pads. The design rules for undistributed I/O pads are illustrated in Table.4 and Figure.4.

\section{Production Capability}

APack has set up a class 100 clean room facility to process 8 -inch $(200 \mathrm{~mm}) \mathrm{Si}$ wafers. The capacity is expandable to 50,000 wafers per month. Preferably the device wafers to be processed at APack facility should not to be thinned using back grinding. The acceptable minimum wafer thickness is $508 \mu \mathrm{m}$ (20 mils). Wafers with a diameter less than 8-inch, as well as the integration of passives on $\mathrm{Si}$ substrate, can be processed in our Phase II facility which is scheduled to be set up in the second half of year 2000. Wafer level flip chip assembly is conducted in a class 1000 clean room facility with a capacity of assembling more than 10 million devices per month. The SIP products can be packed as PQFP, BGA or CSP (chip size package).

\section{Reliability of Solder Bumping and Flip-Chip Assembly}

Reliability of solder bumping and flip chip tiles has been studied. The results of temperature cycling, thermal aging, and temperature humidity tests under various conditions show that APack's solder bumping and flip chip assembly are very robust. Some of the reliability test results are summarized below. 


\section{A. Reliability Studies of Solder Bumps}

Temperature Cycling Test of Solder Bumps

5 wafers with more than 121,000 95Sn5Sb Solder Bumps (220 $\mu \mathrm{m}$ diameter and $140 \mu \mathrm{m}$ height) were subject to temperature cycling between $-55 \sim 125^{\circ} \mathrm{C}$ (10 min. dwell time at each temperature extreme). All the bump's shear strength remained high after 1000 cycles as shown in Figure5 (a).

\section{Thermal Aging Test of Solder Bumps}

2 wafers with more than 48,000 95Sn5Sb Solder Bumps (220 $\mu \mathrm{m}$ diameter and $140 \mu \mathrm{m}$ height) were thermally aged at $150{ }^{\circ} \mathrm{C}$ up to 1000 hours. The bump shear strength remain high after 1000 hours as shown in the Figure 5(b).

Chips with $63 \mathrm{Sn} 37 \mathrm{~Pb}$ eutectic solder bumps $(200 \mu \mathrm{m}$ diameter and $140 \mu \mathrm{m}$ height) were aged at $185^{\circ} \mathrm{C}$ for 1000 hours. It was impressive to find that the bumps remained to be very strong even after being exposed to a high temperature near its melting temperature for extensive time. The average shear strength of the bumps after various test time is presented in the Table 5 .

In another experiment, the $\mathrm{SnPb}$ eutectic bumps were put on a hot plate at $250{ }^{\circ} \mathrm{C}$ under melting condition for 100 minutes. The bumps were re-solidified after cooling down to room temperature and then subject to shear test. Its averaged shear strength is $107 \pm 11$ grams. Still no degradation of bump shear strength was observed.

The robustness of UBM was also demonstrated by successful multiple reflows of $95 \mathrm{Sn} 5 \mathrm{Sb}$ solder bumps (200 $\mu \mathrm{m}$ diameter and $140 \mu \mathrm{m}$ height). The peak heating condition was $260^{\circ} \mathrm{C}, 2 \mathrm{~min}$. The shear strength of the leadfree solder bumps remained high after 10 times of reflows are $168 \pm 18$ grams for 1 reflow, $171 \pm 20$ grams for 5 reflows, $168 \pm 20$ grams for 10 reflows, respectively.

\section{Temperature Humidity Test of Solder Bumps}

48 chips with a total of $748895 \mathrm{Sn} 5 \mathrm{Sb}$ Solder Bumps (350 $\mu \mathrm{m}$ diameter and $109 \mu \mathrm{m}$ height) were accelerated aged in a steam bomb under the following test condition $135^{\circ} \mathrm{C}, 85$ $\%$ RH, $2.7 \mathrm{~atm}$. The solder bumps survived through such harsh condition and their shear strength remained high after the test.

\section{B. Reliability Studies of Flip-Chip Tiles}

Flip Chip Tile as shown in Figure.7 was used for reliability studies. Two chips were assembled on each tile to form a daisy chain of 96 solder joints. Since there is a good match of CTE (coefficient of thermal expansion) between the chips and the Si substrate, no underfill was used on the tile. The results of temperature cycling, thermal aging and temperature humidity tests are summarized below.

\section{Temperature Cycling Test of Flip Chip Tiles}

48 Tiles with a total of 96 chips were assembled using $95 \mathrm{Sn} 5 \mathrm{Sb}$ solder. A total of 4608 solder joints (each with 350 $\mu \mathrm{m}$ diameter and $75 \mu \mathrm{m}$ height) were subject to temperature cycling test between -40 and $125^{\circ} \mathrm{C}$ (15 min. dwell time at each temperature extreme). All samples passed the test. The test results are summarized in Table.6.

\section{Thermal Aging Test of Flip Chip Tiles}

48 Tiles with a total of 96 chips and 4608 solder joints (95Sn5Sb solder joints with $350 \mu \mathrm{m}$ diameter and $75 \mu \mathrm{m}$ height) were aged at $150{ }^{\circ} \mathrm{C}$ for 1000 hours. All the samples passed the test and their results are shown in Table.7.

\section{Temperature Humidity Test of Flip Chip Tiles}

Similar to the previous two tests, 48 Tiles with a total of 96 chips and 4608 solder joints (95Sn5Sb solder with $350 \mu \mathrm{m}$ diameter and $75 \mu \mathrm{m}$ height) were accelerated aged in a steam bomb under $135^{\circ} \mathrm{C}, 85 \% \mathrm{RH}$ and 2.7 atm up to 168 hours. All the samples passed the harsh test and the shear strength of solder joints remained high after the test. The test results are summarized below in Table.8.

\section{Summary}

APack's SIP technology provides a cost-effective alternative to System-On-Chip (SOC) and chips with embedded memory. The process flow and the design rules of the SIP technology have been presented. Various preliminary reliability test results of solder bumps and flip chip tiles have shown that the SIP technology is robust. The reliability of complete SIP, such as in the format of PQFP, BGA or CSM, is yet to be demonstrated on real products. 


\section{References}

1) T. D. Dudderar, Y. Degani, J. G. Spadafora and K. L. Tai "AT\&T m-Surface Mount Assembly: A New Technology for the Large Volume Fabrication of Cost Effective Flip-chip MCMs," Proceedings of International Conference Multichip Modules, p. 266, Denver, CO, April 13-15 (1994).

2) K. L. Tai, R. C. Frye, B. J. Han, M. Y. Lau and D. P. Kossives, "A Chip-on-Chip DSP/SRAM multichip Module," Proc. 1995 Int'l Conf. On Multichip Modules Denver, CO, April 19-21 (1995).

3) Y. L. Low, R. C. Frye and K. J. O'Connor, "Design Methodology for Chip-on-Chip Applications," IEEE Transactions on Components, Packaging and
Manufacturing Technology-Part B, Vol. 21, No.3, August (1998).

4) Y. L. Low and K. J. O'Connor, "Electrical Performance of Chip-on-Chip Modules," IEEE $7^{\text {th }}$ Topic Meeting on Electrical Performance of Electronic Packaging, October 26-28 (1998).

5) K. J. O'Connor, Y. L. Low, J. A. Gregus and Y. Degani, "Memory Performance in Chip-on-Chip Packages: Optimizing Memory/ASIC Integration," 1998 Symposium on IC/Package Design Integration Digest of Technical Papers, p. 16-20, February 2-3 (1998).

6) J. A. Gregus, M. Y. Lau, Y. Degani and K. L. Tai, "Chip Scale Modules for High Level Integration in the $21^{\text {st }}$ Century," Bell Labs Technical Journal, p.116-124, July-September (1998).

\begin{tabular}{|c|c|c|}
\hline Solder Materials & $95 \% \mathrm{Sn} 5 \% \mathrm{Sb}$ & $63 \% \mathrm{Sn} 37 \% \mathrm{~Pb}$ \\
\hline Melting Temperature & $232 \sim 240{ }^{\circ} \mathrm{C}$ & $183{ }^{\circ} \mathrm{C}$ \\
\hline Reflow Temperature & $260{ }^{\circ} \mathrm{C}$ & $210{ }^{\circ} \mathrm{C}$ \\
\hline
\end{tabular}

Table 1. Comparison of solder materials

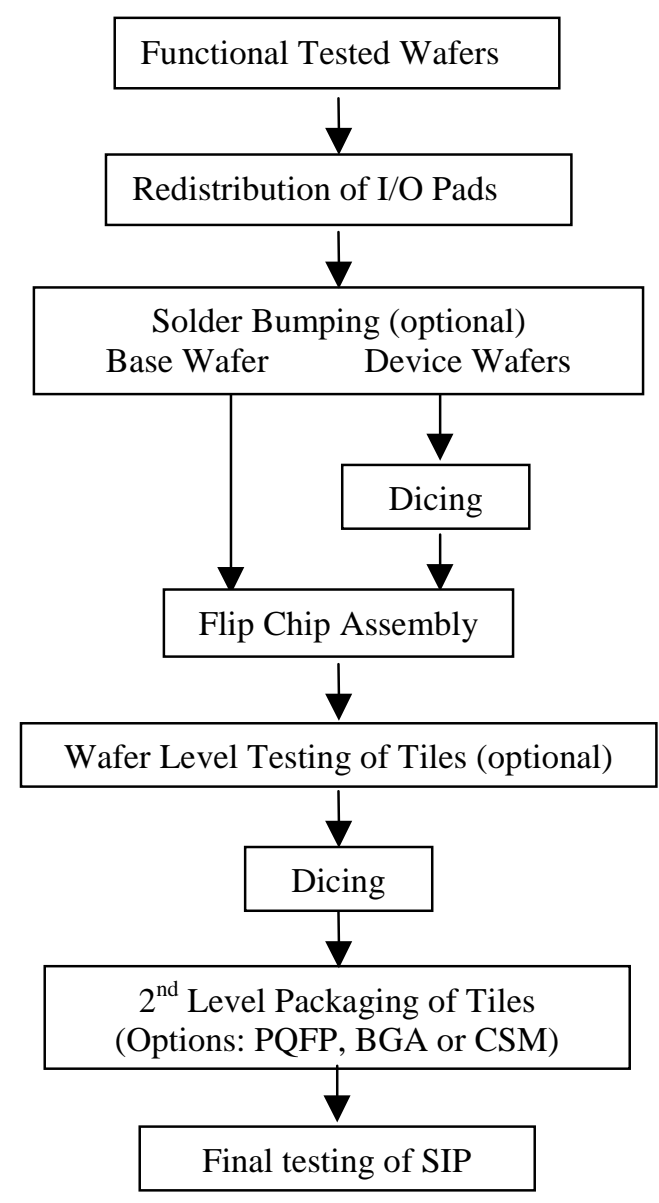

Figure.1 SIP process flow 


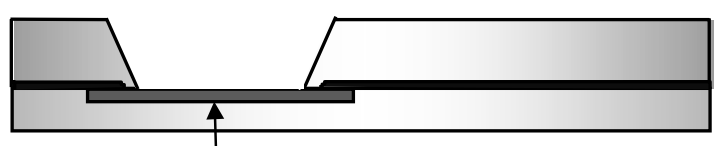

Aluminum I/O Pad
Polyimid

Passivation

Si Wafer

a) Step 1 of I/O redistribution: As-received wafers may or may not have a top layer of

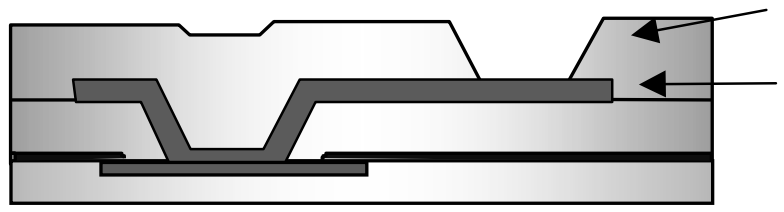

Polyimide

Aluminum

Rerouting

b) Step 2 of I/O redistribution: Aluminum I/O pads are rerouted and an additional polyimide layer is spin-coated and patterned.

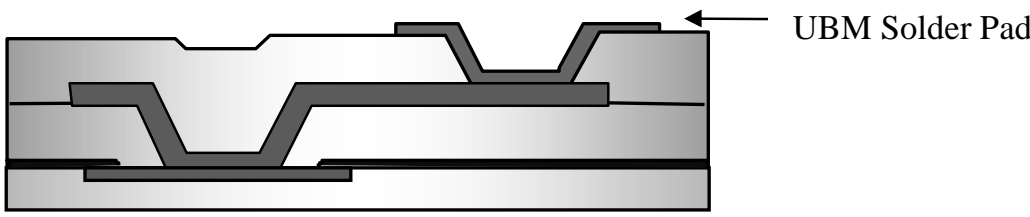

c) Step 3 of I/O redistribution: Under Bump

Metallization (UBM) is sputtered and patterned.

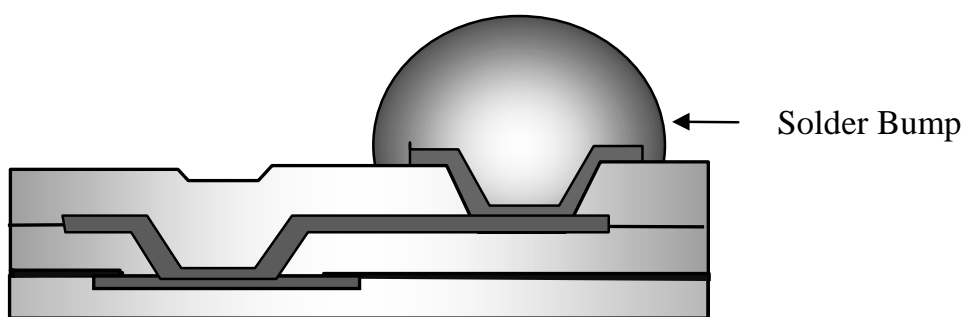

d) Solder Bumping: Solder bumps are formed on UBM using wafer-level printing and reflow processes.

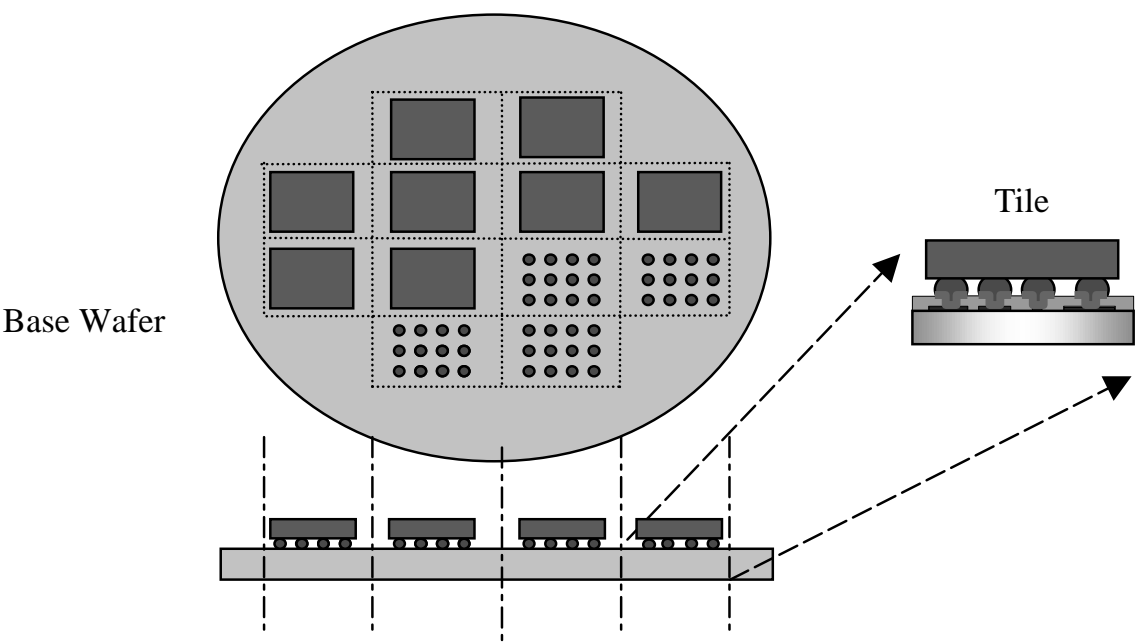

e) Wafer Level Flip Chip Assembly: Good chips are picked from device wafers according to their test results (as presented in wafer maps) and then flip assembled on the substrate using flip chip bonding and reflow processes.

Figure.2 Key process steps of SIP 


\begin{tabular}{|c|c|c|c|c|}
\hline Mask Levels & Materials & Typical Thickness & $\begin{array}{c}\text { Minimum } \\
\text { Feature Size }\end{array}$ & $\begin{array}{c}\text { Preferred } \\
\text { Feature Size }\end{array}$ \\
\hline $\mathrm{D} 1$ & polyimide & $3 \mu \mathrm{m}$ & $15 \mu \mathrm{m}$ & $40 \mu \mathrm{m}$ \\
\hline $\mathrm{M} 1$ & aluminum & $2 \mu \mathrm{m}$ & $20 \mu \mathrm{m}$ & $35 \mu \mathrm{m}$ \\
\hline $\mathrm{D} 2$ & polyimide & $3 \mu \mathrm{m}$ & $15 \mu \mathrm{m}$ & $50 \mu \mathrm{m}$ \\
\hline $\mathrm{UBM}$ & $\mathrm{Cr} / \mathrm{CrCu} / \mathrm{Cu}$ & $1 \mathrm{~K} \AA 3 \mathrm{~K} \AA 6 \mathrm{~K} \AA$ & $100 \mu \mathrm{m}$ & $150 \mu \mathrm{m}$ \\
\hline Solder & $\mathrm{SnSb}$ or $\mathrm{SnPb}$ & $200 \mu \mathrm{m}$ & $75 \mu \mathrm{m}$ & $400 \mu \mathrm{m}$ \\
\hline
\end{tabular}

Table 2. Composition and design values of each mask level

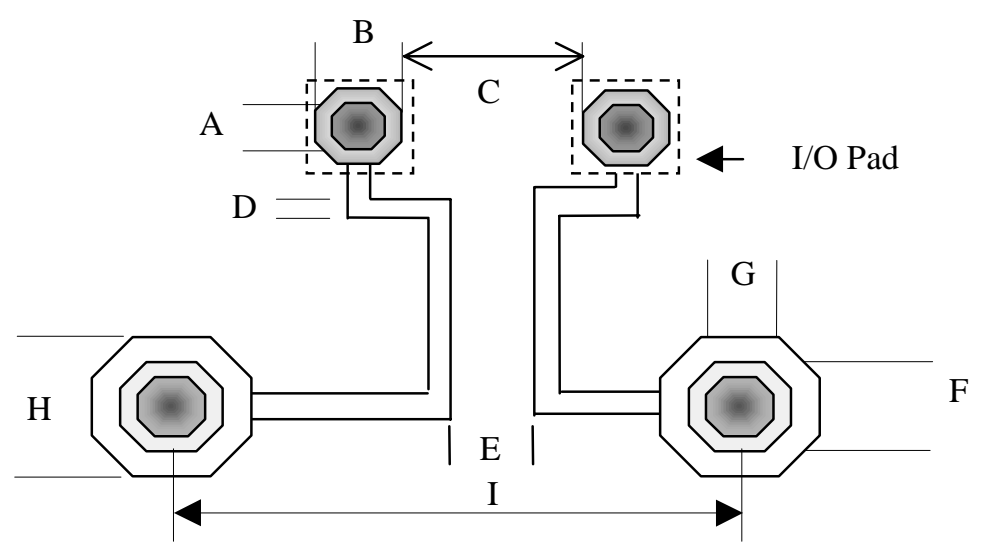

Figure3. I/O redistribution design rules

\begin{tabular}{|c|l|c|c|c|}
\hline Items & \multicolumn{1}{|c|}{ Description } & Mask Level & $\begin{array}{c}\text { Minimum } \\
\text { Dimension }\end{array}$ & Preferred Dimension \\
\hline A & Via diameter of AL I/O pad & D1 & $25 \mu \mathrm{m}$ & $40 \mu \mathrm{m}^{*}$ \\
\hline B & AL I/O via capture pad & M1 & $50 \mu \mathrm{m}$ & $80 \mu \mathrm{m}$ \\
\hline C & Separation of AL I/O via capture pads & M1 & $20 \mu \mathrm{m}$ & $50 \mu \mathrm{m}$ \\
\hline D & Linewidth of AL rerouting path & M1 & $20 \mu \mathrm{m}$ & $35 \mu \mathrm{m}$ \\
\hline E & Separation of AL rerouting paths & M1 & $20 \mu \mathrm{m}$ & $35 \mu \mathrm{m}$ \\
\hline F & AL pad (solder via capture pad) & M1 & $80 \mu \mathrm{m}$ & $100 \mu \mathrm{m}$ \\
\hline G & Via diameter of UBM solder pad & D2 & $60 \mu \mathrm{m}$ & $80 \mu \mathrm{m}$ \\
\hline H & Diameter of UBM solder pad & UBM & $100 \mu \mathrm{m}$ & $150 \mu \mathrm{m}$ \\
\hline I & $\begin{array}{l}\text { Pitch of UBM solder pads } \\
\text { (center-to-center spacing) }\end{array}$ & UBM & $350 \mu \mathrm{m}$ & $>400 \mu \mathrm{m}$ \\
\hline
\end{tabular}

* This dimension may vary depending on resistance requirement.

Table 3. I/O redistribution design rules

Chip Edge

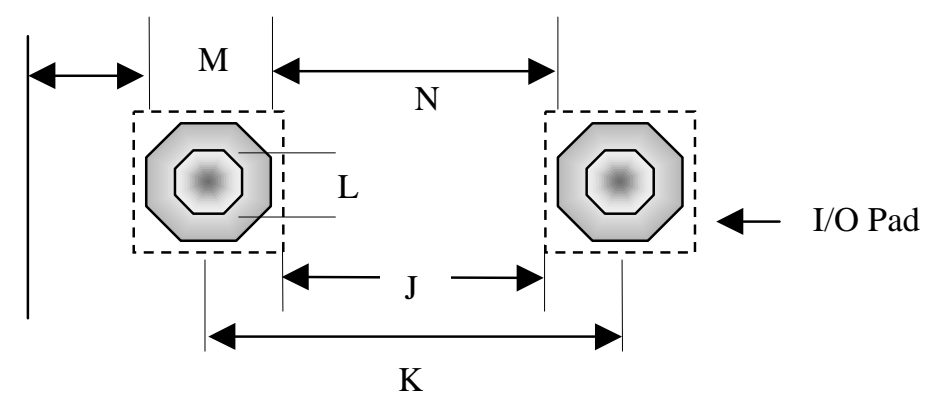

Figure4. Design rules for undistributed I/O 


\begin{tabular}{|c|l|c|c|c|}
\hline Items & \multicolumn{1}{|c|}{ Description } & Mask Level & $\begin{array}{c}\text { Minimum } \\
\text { Dimension }\end{array}$ & Preferred Dimension \\
\hline $\mathrm{J}$ & $\begin{array}{l}\text { Separation of AL I/O pads } \\
\text { (original wire bonding pad on IC) }\end{array}$ & - & $50 \mu \mathrm{m}$ & $100 \mu \mathrm{m}$ \\
\hline $\mathrm{K}$ & Pitch of AL I/O Pads & - & $150 \mu \mathrm{m}$ & $350 \mu \mathrm{m}$ \\
\hline $\mathrm{L}$ & Via diameter of AL I/O pad & D1 & $25 \mu \mathrm{m}$ & $40 \mu \mathrm{m}$ \\
\hline $\mathrm{M}$ & Diameter of UBM solder pad & UBM & $75 \mu \mathrm{m}$ & $100 \mu \mathrm{m}$ \\
\hline $\mathrm{N}$ & Separation of UBM solder pads & UBM & $75 \mu \mathrm{m}$ & $100 \mu \mathrm{m}$ \\
\hline $\mathrm{O}$ & $\begin{array}{l}\text { Separation between UBM solder pad } \\
\text { edge and chip edge }\end{array}$ & UBM & $75 \mu \mathrm{m}$ & $100 \mu \mathrm{m} \#$ \\
\hline
\end{tabular}

* This dimension may vary with resistance requirement.

\# This dimension may vary with next level assembly process.

Table 4. Design rules for undistributed I/O

150

苟

110

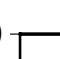

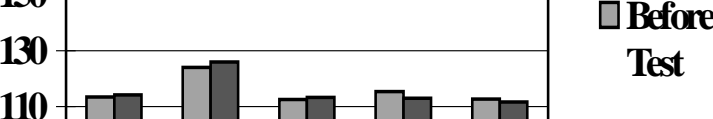

90

70

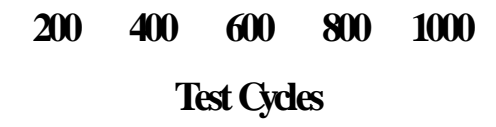

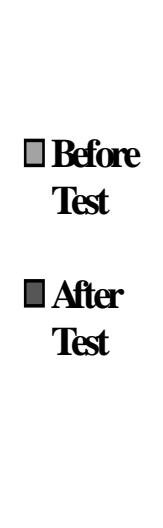

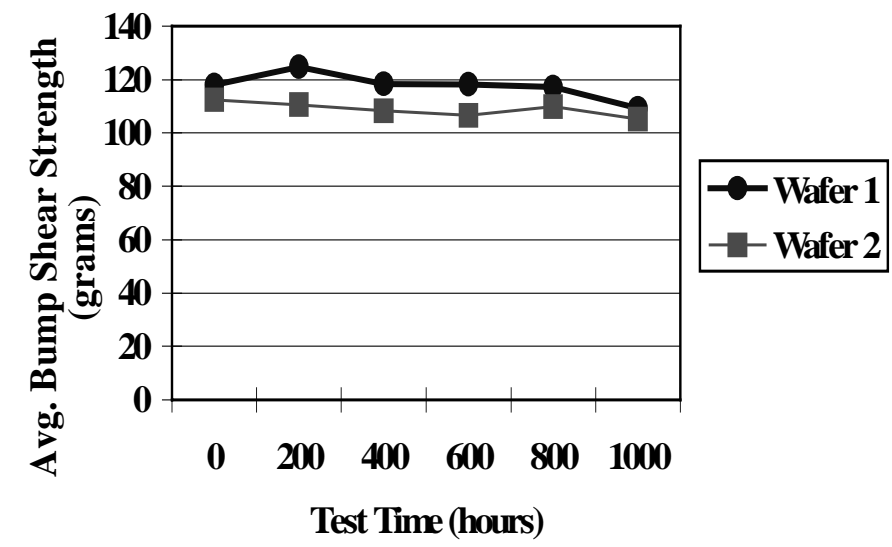

Figure 5. (a) Temperature aging test of solder bumps. (b) Thermal aging test of solder bumps

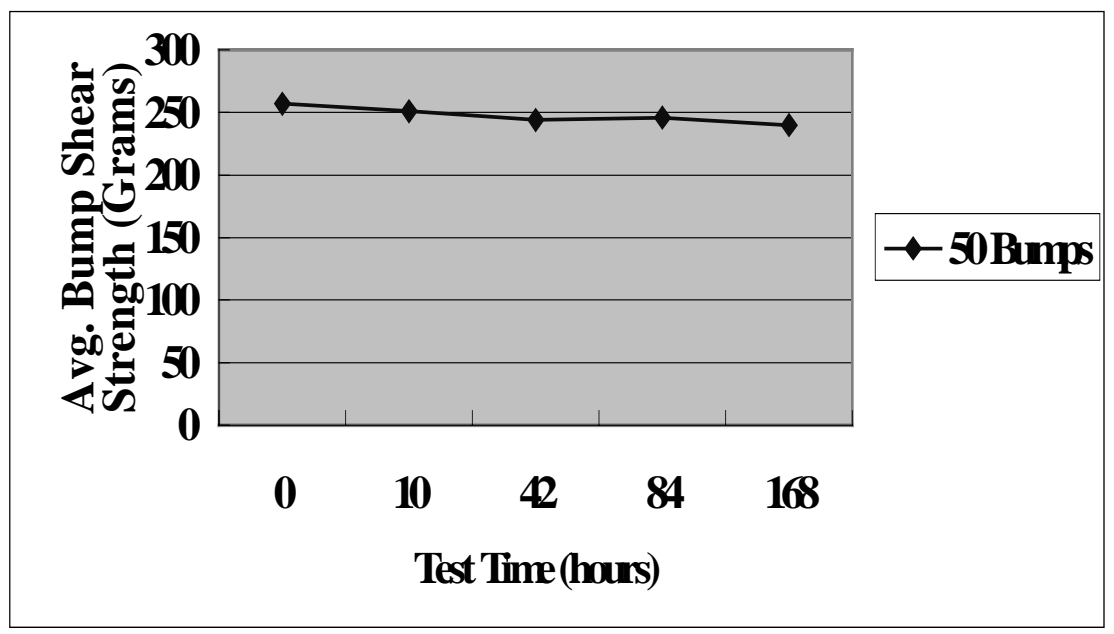

Figure 6. Temperature humidity test of solder bumps 


\begin{tabular}{|l|c|c|c|c|}
\hline Test Time (hours) & 0 & 100 & 500 & 1000 \\
\hline Avg. Shear Strength of 50 Bumps (grams) & $109 \pm 10$ & $107 \pm 11$ & $106 \pm 10$ & $100 \pm 11$ \\
\hline
\end{tabular}

Table 5. Average shear strength of the bumps after various testing time at $185^{\circ} \mathrm{C}$.

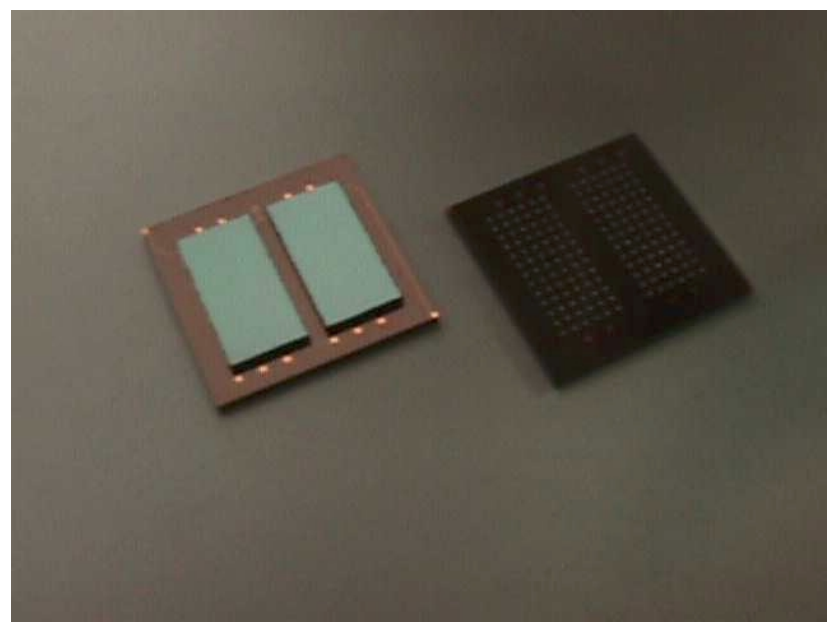

Figure 7. Flip-chip testing tile

\begin{tabular}{|l|c|c|c|c|c|}
\hline Test Cycles & 0 & 100 & 250 & 500 & 1000 \\
\hline Failed Chips/Tested Chips & $0 / 96$ & $0 / 96$ & $0 / 84$ & $0 / 72$ & $0 / 60$ \\
Failed Joints/Tested Joints & $0 / 4608$ & $0 / 4608$ & $0 / 4032$ & $0 / 3456$ & $0 / 2880$ \\
\hline Avg. Shear Strength of 12 chips & $25 \pm 4$ & $19 \pm 3$ & $20 \pm 2$ & $19 \pm 2$ & $18 \pm 3$ \\
(3x16 bumps per chip) & $\mathrm{Kg}$ & $\mathrm{Kg}$ & $\mathrm{Kg}$ & $\mathrm{Kg}$ & $\mathrm{Kg}$ \\
\hline
\end{tabular}

Table 6. Temperature cycling test of flip-chip tiles

\begin{tabular}{|l|c|c|c|c|c|c|c|}
\hline Test Time (hours) & 0 & 24 & 120 & 216 & 504 & 768 & 1008 \\
\hline Failed Chips/Tested Chips & $0 / 96$ & $0 / 96$ & $0 / 96$ & $0 / 84$ & $0 / 72$ & $0 / 60$ & $0 / 48$ \\
Failed Joints/Tested Joints & $0 / 4608$ & $0 / 4608$ & $0 / 4608$ & $0 / 4032$ & $0 / 3456$ & $0 / 2880$ & $0 / 2304$ \\
\hline Avg. Shear Strength & $25 \pm 4$ & - & $16 \pm 2$ & $15 \pm 3$ & $13 \pm 1$ & $13 \pm 2$ & $12 \pm 2$ \\
of 12 chips & $\mathrm{Kg}$ & & $\mathrm{Kg}$ & $\mathrm{Kg}$ & $\mathrm{Kg}$ & $\mathrm{Kg}$ & $\mathrm{Kg}$ \\
(3x16 bumps per chip) & & & & & & & \\
\hline
\end{tabular}

Table 7. Thermal aging test of flip-chip tiles

\begin{tabular}{|l|c|c|c|c|c|}
\hline Test Time (hours) & 0 & 10 & 42 & 84 & 168 \\
\hline Failed Chips/Tested Chips & $0 / 96$ & $0 / 96$ & $0 / 96$ & $0 / 84$ & $0 / 72$ \\
Failed Joints/Tested Joints & $0 / 4608$ & $0 / 4608$ & $0 / 4608$ & $0 / 4032$ & $0 / 3456$ \\
\hline Avg. Shear Strength of 12 chips & $25 \pm 4$ & - & $16 \pm 3$ & $16 \pm 3$ & $12 \pm 2$ \\
(3x16 bumps per chip) & $\mathrm{Kg}$ & & $\mathrm{Kg}$ & $\mathrm{Kg}$ & $\mathrm{Kg}$ \\
\hline
\end{tabular}

Table 8. Temperature humidity test of flip-chip tiles 